\title{
Normocapnic High-frequency Oscillatory Ventilation Affects Differently Extrapulmonary and Pulmonary Forms of Acute Respiratory Distress Syndrome in Adults
}

\author{
J. PACHL, K. ROUBÍK ${ }^{1}$, P. WALDAUF, M. FRIC, V. ZÁBRODSKÝ \\ University Department of Anesthesiology and Critical Care Medicine, Third Faculty of Medicine, \\ Charles University, and ${ }^{1}$ Faculty of Biomedical Engineering, Czech Technical University, Prague, \\ Czech Republic
}

Received February 28, 2005

Accepted March 4, 2005

On-line available April 26, 2005

\begin{abstract}
Summary
The recently reported differences between pulmonary and extrapulmonary acute respiratory distress syndromes $\left(\mathrm{ARDS}_{\mathrm{p}}, \mathrm{ARDS}_{\text {exp }}\right)$ are the main reasons of scientific discussion on potential differences in the effects of current ventilatory strategies. The aim of this study is to assess whether the presence of $\mathrm{ARDS}_{\mathrm{p}}$ or $\mathrm{ARDS}_{\text {exp }}$ can differently affect the beneficial effects of high-frequency oscillatory ventilation (HFOV) upon physiological and clinical parameters. Thirty adults fulfilling the ARDS criteria were indicated for HFOV in case of failure of conventional ventilation strategy. According to the ARDS type, each patient was included either in the group of patients with $\mathrm{ARDS}_{\mathrm{p}}$ or $\mathrm{ARDS}_{\text {exp. }}$. Six hours after normocapnic HFOV introduction, there was no significant increase in $\mathrm{PaO}_{2} / \mathrm{F}_{1} \mathrm{O}_{2}$ in $\mathrm{ARDS}_{\mathrm{p}}$ group (from $129 \pm 47$ to $133 \pm 50$ Torr), but a significant improvement was found in $\operatorname{ARDS}_{\text {exp }}$ (from $114 \pm 54$ to $200 \pm 65$ Torr, $\mathrm{p}<0.01$ ). Despite the insignificant difference in the latest mean airway pressure (MAP) on conventional mechanical ventilation (CMV) between both groups, initial optimal continuous distension pressure (CDP) for the best $\mathrm{PaO}_{2} / \mathrm{F}_{1} \mathrm{O}_{2}$ during HFOV was $2.0 \pm 0.6 \mathrm{kPa}$ in $\mathrm{ARDS}_{\mathrm{p}}$ and $2.8 \pm 0.6 \mathrm{kPa}$ in $\mathrm{ARDS}_{\text {exp }}(\mathrm{p}<0.01)$. HFOV recruits and thus it is more effective in $\mathrm{ARDS}_{\text {exp. }}$. $\mathrm{ARDS}_{\text {exp }}$ patients require higher CDP levels than $\mathrm{ARDS}_{\mathrm{p}}$ patients. The testing period for positive effect of HFOV is recommended not to be longer than 24 hours.
\end{abstract}

Key words

High-frequency ventilation $\bullet$ High-frequency oscillation $\bullet$ ARDS $\bullet$ Hypoxemic index $\bullet$ Mechanical ventilation

\section{Introduction}

The heterogeneity of ARDS group has been recently discussed in a number of studies also focusing on the differences between pulmonary $\left(\mathrm{ARDS}_{\mathrm{p}}\right)$ and extrapulmonary $\left(\mathrm{ARDS}_{\mathrm{exp}}\right)$ forms of ARDS. The main discussed aspects include differences in epidemiology, pathophysiology, morphology, respiratory mechanics, prone positioning, response to pharmacological agents and ventilatory strategies (Beloucif et al. 1998, Lim et al. 2001, Pelosi et al. 2001, Pugin et al. 1996). The low tidal volume strategy of conventional ventilation demonstrates 
a reduction in mortality in ARDS, but it fails to show different effects between $\mathrm{ARDS}_{\mathrm{p}}$ and $\mathrm{ARDS}_{\text {exp }}$ subgroups (Gattinoni et al. 1998). High-frequency oscillatory ventilation used for ARDS treatment offers potential advantages of lower tidal volumes and lower pressure changes conducted on such a value of continuous distension pressure on which the oxygenation reaches its maximal value.

A few studies investigated the physiological effects of HFOV in selected populations of patients. This is the first study investigating the differences in HFOV effect in pulmonary and extrapulmonary ARDS patients separately. This is an extremely important approach, because it is evident that each ventilatory strategy can be more or less beneficial considering the pathophysiology of different causes of respiratory failure. The rationale is that we should expect better response of HFOV due to an increase in mean airway pressure in patients suffering from extrapulmonary form of ARDS resulting from a likely increased amount of recruitable atelectatic lung tissue. The aim of this study is to examine whether HFOV as an unconventional type of ventilation affects differently the physiological and clinical parameters of $\mathrm{ARDS}_{\mathrm{p}}$ and $\mathrm{ARDS}_{\text {exp }}$ patients.

\section{Methods}

This study has been approved by the Ethical Committee of Charles University, Third Faculty of Medicine, prior to the commencement of the study.

A group of 30 adult patients ( $55 \pm 19$ years old, $\mathrm{M} / \mathrm{F}=16 / 14)$ fulfilling the diagnostic criteria of ARDS $\left(\mathrm{PaO}_{2} / \mathrm{F}_{1} \mathrm{O}_{2}<200\right.$ Torr, PCWP $\leq 18$ Torr and the X-ray criteria), as defined by the American-European Consensual Conference (Bernard et al. 1994, International Consensus Conferences in Intensive Care Medicine 1999), were introduced into the study. HFOV was indicated in the case of failure of conventional ventilation $\left(\mathrm{P}_{\text {plateau }}>3.5 \mathrm{kPa}, \mathrm{PEEP}>1 \mathrm{kPa}\right.$ and $\left.\mathrm{F}_{\mathrm{I}} \mathrm{O}_{2}>0.6\right)$.

Before HFOV initiation, the parameters of conventional mechanical ventilation (CMV) were recorded: tidal volume $\left(\mathrm{V}_{\mathrm{T}}\right)$, ventilatory rate $(\mathrm{f})$, mean airway pressure (MAP), inspiratory oxygen fraction $\left(\mathrm{F}_{\mathrm{I}} \mathrm{O}_{2}\right)$, compliance of the respiratory system $\left(\mathrm{C}_{\mathrm{rs}}\right)$, airway resistance $\left(\mathrm{R}_{\mathrm{aw}}\right)$ and arterial blood gases $\left(\mathrm{PaO}_{2}, \mathrm{PaCO}_{2}\right.$ and $\mathrm{pH}$ ). The Lung Injury Score, SOFA score, hypoxemic index $\left(\mathrm{PaO}_{2} / \mathrm{F}_{1} \mathrm{O}_{2}\right)$ and oxygenation index (OI) were evaluated.
After HFOV initiation (3100B, SensorMedics), the trends of the following ventilatory parameters were recorded: continuous distension pressure (CDP), pressure amplitude $(\Delta \mathrm{P}), \mathrm{V}_{\mathrm{T}}, \mathrm{R}_{\mathrm{aw}}, \mathrm{OI}$ and $\mathrm{PaO}_{2} / \mathrm{F}_{\mathrm{I}} \mathrm{O}_{2}$. Finally, the form of ARDS (pulmonary $\mathrm{ARDS}_{\mathrm{p}}$ or extrapulmonary $\mathrm{ARDS}_{\text {exp }}$ ) was decided by two independent specialists according to the characteristics and pathophysiological differences in $\mathrm{ARDS}_{\mathrm{p}}$ and $\mathrm{ARDS}_{\text {exp }}$ patients (Gattinoni et al. 1998).

A special equipment for HFOV monitoring and measurement of tidal volume and airway resistance was designed, developed and properly tested. The main advantage of the system is continuous measurement of delivered tidal volume and airway resistance during both conventional and high-frequency oscillatory ventilation.

The system consists of a small mechanical couple, pressure and airflow sensors, analogue-to-digital converters controlled by a microprocessor and a standard RS232 communication serial port. Measuring ports of airway pressure and airflow are incorporated in a special couple. The couple can be easily introduced into the patient's circuit, because it is equipped with a standard M15 cone at the side predetermined for connection to a ventilator, and F15 cone at the side of patient. Placement of this couple into the patient's circuit between a ventilator (CMV or HFOV) and a patient is the only operation that is necessary for proper work of the monitoring system.

Airflow is measured as a pressure difference appearing on a fix constriction in airway diameter inside the couple. The developed pressure difference is measured by a differential pressure sensor (186PC03DT, Honeywell) connected to the couple by PVC hoses $120 \mathrm{~mm}$ long and $2 \mathrm{~mm}$ in diameter. Airway pressure is measured $10 \mathrm{~mm}$ behind the airflow measurement point in the couple towards a patient. Diameter of the measurement point is $1.2 \mathrm{~mm}$ and it is connected to a pressure sensor (186PC03DT, Honeywell) by a PVC hose $120 \mathrm{~mm}$ long and $2 \mathrm{~mm}$ in diameter. The pressure transducers lead-in dimensions, a low size of the transducer measuring cell and a short response time of the transducers assure a very small dynamic error of the measuring system. The time constant of the lead-in is $\tau=$ 7.6. $10^{-4} \mathrm{~s}$. The catalogue value of the response time of the pressure sensors is $10^{-3} \mathrm{~s}$.

Signals from the airflow and pressure sensors are amplified, low-pass filtered and sampled by 12-bit analogue-to-digital converters (TLC 2543, Texas Instruments) with a sampling rate of $2500 \mathrm{~Hz}$. The 
acquired digital data are transmitted to a PC computer (preferably a notebook computer) using RS232 serial line. The data are processed in the computer by special HiFi software.

Changes of gas flow characteristics with gas velocity changes, mechanical asymmetries, etc., are causes of non-linearities and systematic errors of airflow measurement. Furthermore, very different diameters of the measurement point and the conducting tube and a high velocity of the gas in the measurement point in the tube also cause an error of pressure measurement. All these errors and nonlinearities are compensated in the computer by the HiFi software. After the corrections, the values of airflow are calculated from the measured pressure difference and delivered tidal volume is computed by numerical integration of the airflow course. Values of airway resistance $R_{a w}$ are calculated by the software from the course of proximal airway pressure and airflow using an algorithm described by Roubík et al. (1998).

Constants in all equations used for the corrections and recalculations have been obtained by interpolation of measured static curves using the leastsquare method. A physical model of the respiratory system was used during pressure calibration. The model consists of a rigid volume and an endotracheal cannula. Points of the static curve have been determined as the differences between pressure recorded by the pressure transducer calibrated at the measurement point and pressure recorded inside the model volume representing the lung compliance. For airflow calibration, a gasmeter (Prema, Chirana) was used during the steady-state measurements. Gas used for all the calibrations was a mixture of air and oxygen at $37{ }^{\circ} \mathrm{C}$, where the total oxygen content was $60 \%$. Temperature of all parts of the model was also $37{ }^{\circ} \mathrm{C}$. Humidity of the gas mixture was $100 \%$.

In order to verify accuracy of the airflow and volume measurement, a special apparatus generating precisely known volumes has been constructed. The apparatus consists of a calibrated glass syringe and a crank mechanism providing cyclical linear shifts of the syringe piston. The piston mechanism is driven by a DC motor. Calibrating volumes can be adjusted mechanically by setting the amplitude of the piston oscillations. Frequency of the generated waves can be adjusted by the motor speed. Airflow signals generated by this apparatus are very close to the sinusoidal waves. The tested measuring system was connected to the output port of the syringe before calibration.

Despite the fact that the volume is adjustable by the piston amplitude, the output port of the syringe and the connected measuring system represent a pneumatic resistance for the moving gas. The compressible volume under the piston can affect the actually generated volume, which is slightly lower than the set volume corresponding to the volume tides produced by the piston. The main cause of this deviation is a pressure difference between the inner and outer syringe space caused by an insufficient time to achieve pressure equilibrium through the airway resistance during quite fast oscillations. The deviation was described theoretically by differential equations. They were solved numerically by an iterative algorithm. Results of the numerical simulations confirmed that the deviation is very small, less than $0.35 \%$ at oscillatory frequency $5 \mathrm{~Hz}$ and less than $1.25 \%$ at $10 \mathrm{~Hz}$. Accuracy of the measuring system, described as a difference between measured tidal volume and volume set by the calibrating apparatus, was always less than $3.5 \%$ for a wide range of tidal volumes and ventilatory frequencies, the typical deviations were $0.25 \%$ at $5 \mathrm{~Hz}$ and $1 \%$ at $10 \mathrm{~Hz}$. These results, combined with results of the steady-state measurement, confirm the accuracy and suitability of the measuring system for HFOV monitoring.

Initial continuous distension pressure (CDP) during HFOV initiation was set to $0.5 \mathrm{kPa}$ above the latest level of MAP during preceding conventional mechanical ventilation, $\mathrm{F}_{\mathrm{I}} \mathrm{O}_{2}$ HFOV $=\mathrm{F}_{\mathrm{I}} \mathrm{O}_{2 \mathrm{CMV}}, \mathrm{T}_{\mathrm{I}} / \mathrm{T}=0.5$, bias flow $=40-60 \mathrm{l} / \mathrm{min}$. Normocapnia was achieved by iterative changes of $\Delta \mathrm{P}$ that is the parameter controlling the delivered tidal volume $\mathrm{V}_{\mathrm{T}}$ on the $\mathrm{HFO}$ ventilator. Optimal initial CDP was found as a pressure ensuring the best possible oxygenation $\left(\mathrm{PaO}_{2}\right)$. Later, continuous distension pressure was decreased gradually according to the development of oxygenation and mechanical properties of the respiratory system. When HFOV did not cause a positive effect, i.e. no improvement in hypoxemic index $\mathrm{PaO}_{2} / \mathrm{F}_{\mathrm{I}} \mathrm{O}_{2}$ was observed, conventional mechanical ventilation was introduced again. In this case, the return to conventional ventilation was performed no later than 24 hours after the initiation of HFOV. When HFOV was effective, CDP was gradually decreased to $1.8 \mathrm{kPa}$ and the patients were weaned on a conventional ventilator.

HFOV was introduced repetitively in 9 patients for two possible reasons: a deterioration in oxygenation occurred after switching to conventional ventilation in comparison with the preceding HFOV period, or 
conventional mechanical ventilation did not lead to an improvement in oxygenation. These 9 patients were included into the study group, but only their first HFOV applications were evaluated.

The difference in HFOV effect between the $\mathrm{ARDS}_{\mathrm{p}}$ and $\mathrm{ARDS}_{\text {exp }}$ groups is described by difference in hypoxemic index $\mathrm{PaO}_{2} / \mathrm{F}_{\mathrm{I}} \mathrm{O}_{2}$. Other parameters, as optimal initial CDP for the best oxygenation, tidal volume, etc. were analyzed as well.

Results of the study are presented as a mean value \pm standard deviation (SD). The assessment of the statistical significance of the differences or changes in results was calculated using the two-tail dependent or independent Student's t-test. In the case of non-normal distribution (decided by Shapiro-Wilk test) the MannWhitney U-test was used. Symbol p stands for statistical significance level.

\section{Results}

From the group of 30 patients, 15 patients suffered from extrapulmonary form of ARDS (ARDS exp $_{\text {) }}$ and 15 from pulmonary form of ARDS $\left(\operatorname{ARDS}_{\mathrm{p}}\right)$. Values of selected physiological and clinical parameters in both groups are presented in Table 1. Diagnostic profile as a reason of ARDS development is described in Table 2.

The average duration of CMV before HFOV was $7.7 \pm 6.4$ days in the whole study group, $10.7 \pm 5.9$ days in $\mathrm{ARDS}_{\mathrm{p}}$ and $4.95 \pm 5.3$ days in $\mathrm{ARDS}_{\text {exp }}$ patients. The average duration of HFOV was $25.8 \pm 26.5$ hours in the whole group, $15.9 \pm 13.7$ hours in $\mathrm{ARDS}_{\mathrm{p}}$ and $34.8 \pm 30.9$ hours in $\mathrm{ARDS}_{\text {exp }}$ patients.

Table 1. Characteristics of the ARDS $S_{p}$ and $A R D S_{\text {exp }}$ subgroups

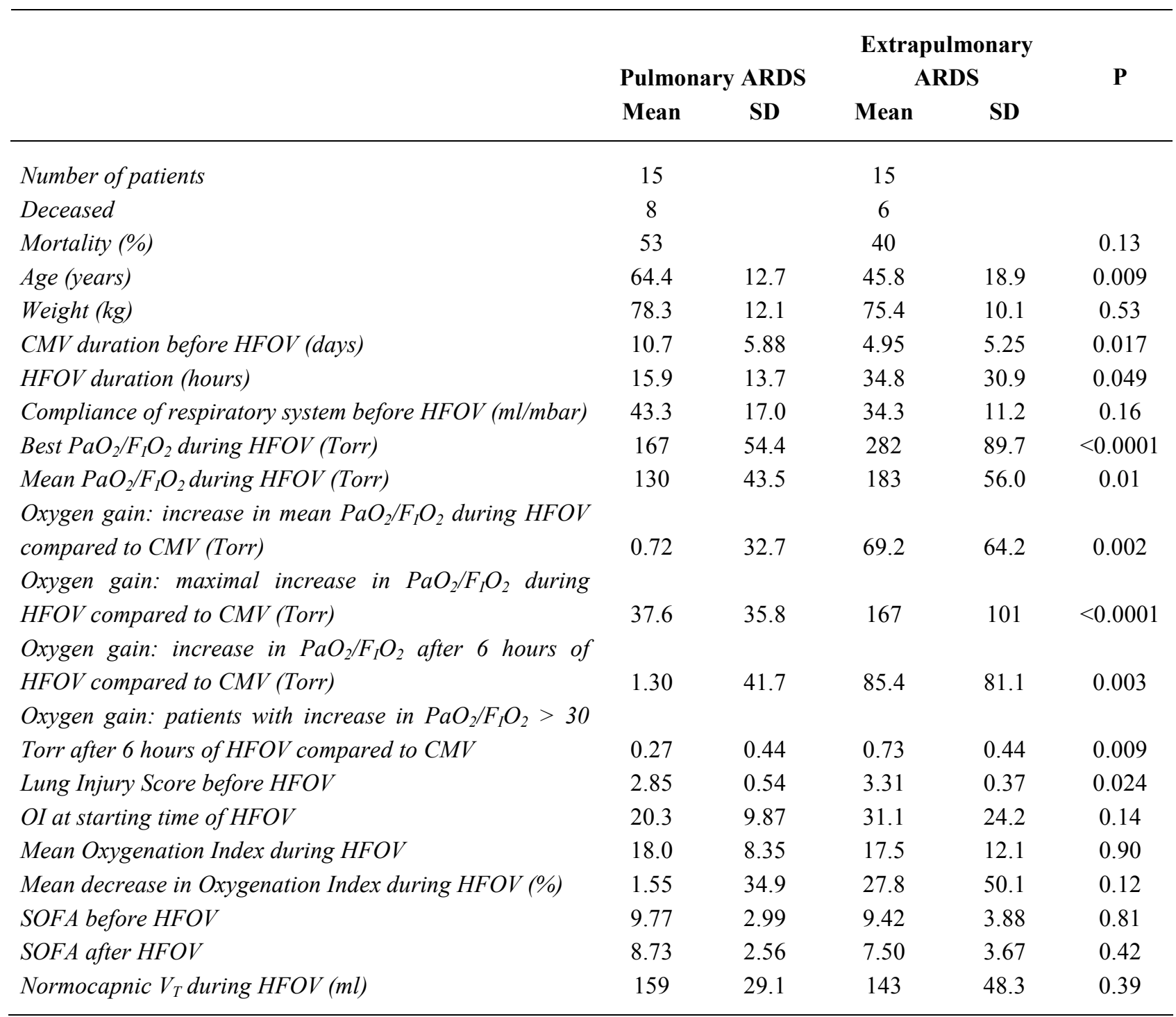


Table 2. Incidence of the diagnoses in the $A R D S_{p}$ and $A R D S_{\text {exp }}$ subgroups

\begin{tabular}{llc}
\hline Diagnosis & ARDS type & $\begin{array}{c}\text { Number of } \\
\text { patients }\end{array}$ \\
\hline Pneumonia & ARDS $_{\mathrm{p}}$ & 14 \\
Sepsis & ARDS $_{\exp }$ & 10 \\
Major trauma & ARDS $_{\text {exp }}$ & 3 \\
Pancreatitis & ARDS $_{\text {exp }}$ & 2 \\
Lung contusion & ARDS $_{\mathrm{p}}$ & 1 \\
\hline
\end{tabular}

Before the introduction of HFOV the average values of $\mathrm{PaO}_{2} / \mathrm{F}_{\mathrm{I}} \mathrm{O}_{2}$ were $129 \pm 47$ Torr in $\mathrm{ARDS}_{\mathrm{p}}$ and $114 \pm 53$ Torr in $\mathrm{ARDS}_{\text {exp }}$ (Fig. 1). There was no significant difference between the groups $(p>0.4)$. Characteristics of $\mathrm{PaO}_{2} / \mathrm{F}_{\mathrm{I}} \mathrm{O}_{2}$ six hours after HFOV initiation are presented in Figure 2. Average values of $\mathrm{PaO}_{2} / \mathrm{F}_{\mathrm{I}} \mathrm{O}_{2}$ were $130 \pm 44$ Torr in $\mathrm{ARDS}_{\mathrm{p}}$ and $183 \pm 56$ Torr in ARDS $_{\text {exp }}$. There was a significant difference between the groups $(\mathrm{p}<0.01)$ and a significant improvement in $\mathrm{PaO}_{2} / \mathrm{F}_{\mathrm{I}} \mathrm{O}_{2}$ in $\mathrm{ARDS}_{\text {exp }}$ group $(\mathrm{p}<0.01)$ compared to the $\mathrm{ARDS}_{\mathrm{p}}$ group.

There was no significant difference between the latest level of mean airway pressure (MAP) during CMV $\left(1.9 \pm 0.5 \mathrm{kPa}\right.$ in $\mathrm{ARDS}_{\mathrm{p}}$ and $2.2 \pm 0.5 \mathrm{kPa}$ in $\left.\mathrm{ARDS}_{\text {exp }}\right)$ (Fig. 3). Comparison of differences between the first optimal CDP during HFOV and the last MAP during CMV (i.e. CDP-MAP) in both $\mathrm{ARDS}_{\mathrm{p}}$ and $\mathrm{ARDS}_{\text {exp }}$ groups shows a significant difference $(p<0.01)$ (Fig. 4). Absolute levels of CDP in one hour of HFOV usage were $2.0 \pm 0.6 \mathrm{kPa}$ in $\mathrm{ARDS}_{\mathrm{p}}$ and $2.8 \pm 0.6 \mathrm{kPa}$ in $\mathrm{ARDS}_{\text {exp }}$.

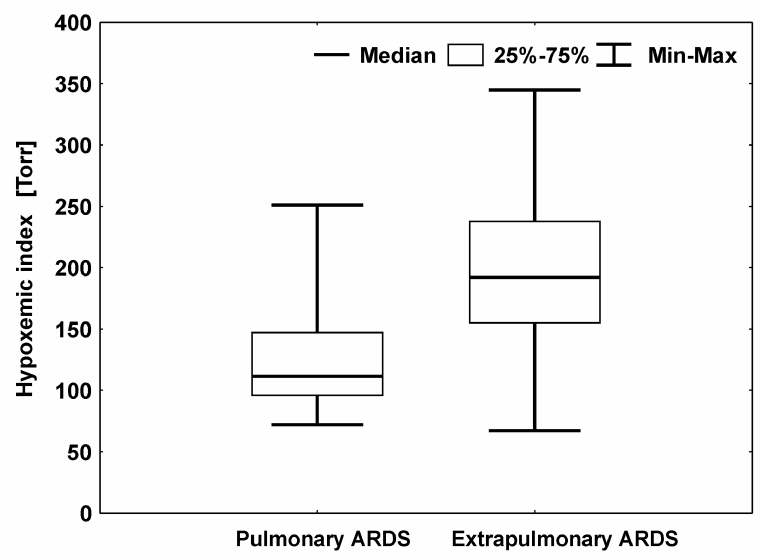

Fig. 1. Hypoxemic index in pulmonary and extrapulmonary ARDS groups during CMV before HFOV introduction

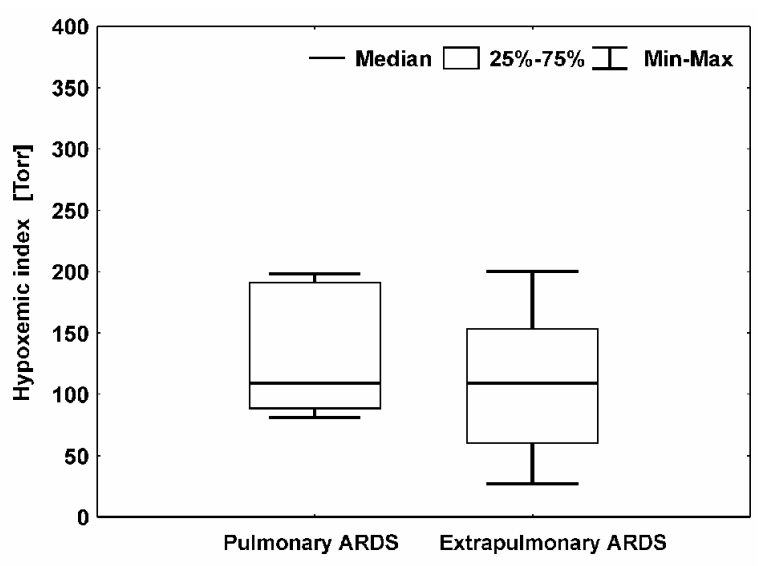

Fig. 2. Hypoxemic index in pulmonary and extrapulmonary ARDS groups after 6 hours of HFOV

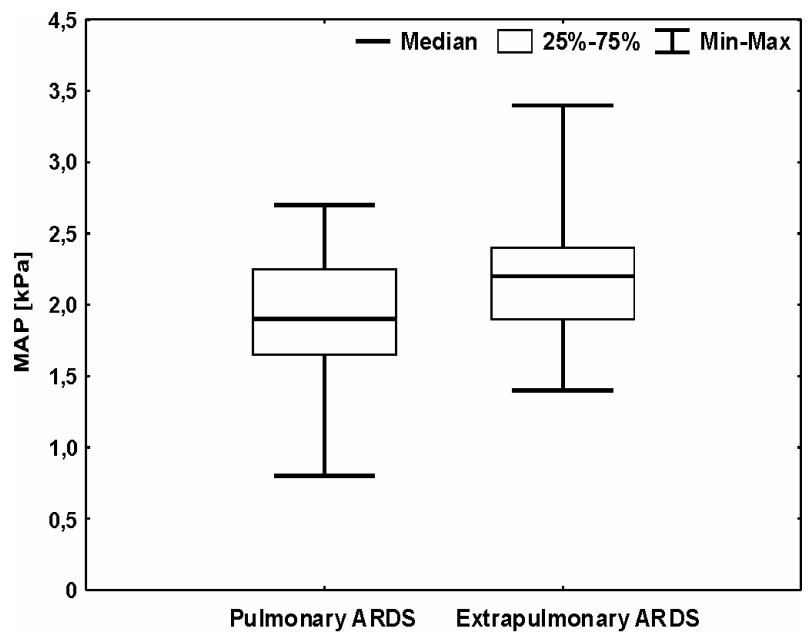

Fig. 3. Difference between the latest mean airway pressure (MAP) values during CMV in pulmonary and extrapulmonary ARDS groups before HFOV introduction

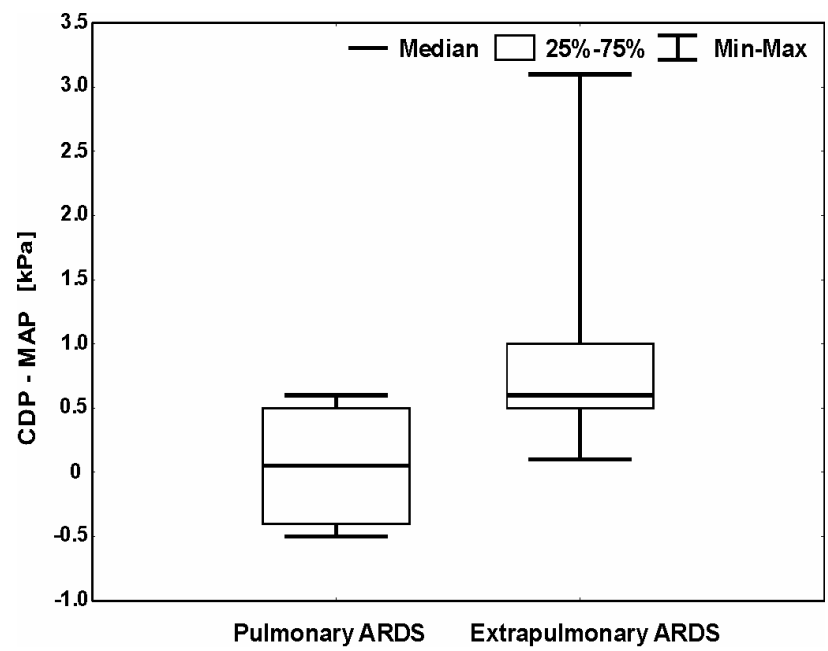

Fig. 4. Difference between CDP level, ensuring the best oxygenation in the initial period of HFOV, and the latest MAP on CMV in pulmonary and extrapulmonary ARDS groups 
Thanks to the measuring and monitoring system connected to the HFO ventilator, the value of tidal volume ensuring normocapnic $\mathrm{HFOV}$ at $5 \mathrm{~Hz}$ was identified at a level of $2.2 \pm 0.5 \mathrm{ml} / \mathrm{kg}$. There was no significant difference in normocapnic $\mathrm{V}_{\mathrm{T}}$ between ARDS $_{\mathrm{p}}$ $(2.14 \pm 0.46 \mathrm{ml} / \mathrm{kg})$ and $\mathrm{ARDS}_{\exp }(2.17 \pm 0.54 \mathrm{ml} / \mathrm{kg})$ groups.

\section{Discussion}

High frequency oscillatory ventilation (HFOV) provides an attractive alternative to conventional ventilation and it seems to suite ideally as a lung protective strategy due to the possibility of low tidal volumes even below the anatomical dead space and low pressure fluctuations in the distal airways at a titrated level of continuous distension pressure (Ferguson et al. 2001). Recent discussion is focused on problems as to who is the ideal candidate for HFOV, when should HFOV be applied, what is the best technique of HFOV application and when and how should a patient on HFOV be weaned or be converted back to conventional ventilation (Singh et al. 2002).

The difference in respiratory mechanics in $\mathrm{ARDS}_{\mathrm{p}}$ and $\mathrm{ARDS}_{\text {exp }}$ patients was presented by Gattinoni et al. (1998). Using excellent conventional ventilation study they did not find a different mortality and duration of intensive care unit stay between $\mathrm{ARDS}_{\mathrm{p}}$ and $\mathrm{ARDS}_{\text {exp }}$ patients. The results of the study have shown a difference in pulmonary and chest wall elastances between the studied subgroups of ARDS. Particularly the pressure volume characteristics on different PEEP levels suggested a better recruitment of $\mathrm{ARDS}_{\text {exp }}$ lungs. These results and our clinical experience in adults and children (Pachl et al. 2004) supported our decision to conduct an evaluation of HFOV effects in $\mathrm{ARDS}_{\mathrm{p}}$ and $\mathrm{ARDS}_{\text {exp }}$ subgroups. No data focusing on this problem has been presented yet (Andersen et al. 2002, Derdak et al. 2002, Fort et al. 1997, Mehta et al. 2001).

Until now, clinicians who use this regimen of unconventional ventilation must rely on their assessment of sufficiency and safety of excursions of the patient's chest wall induced by the HFO ventilator. Our normocapnic HFOV study was based on the possibility of continuous monitoring of minute ventilation, tidal volume and airway resistance. At the beginning of our study, we started to evaluate average $\mathrm{V}_{\mathrm{T}}$ for normocapnic ventilation during HFOV with a ventilatory rate of $5 \mathrm{~Hz}$. Where possible we tried to use such values of $\mathrm{V}_{\mathrm{T}}$ that were able to ensure both normocapnia and optimal oxygen tension on the alveo-capillary membrane. We should stress the importance of adequate, probably normocapnic, $\mathrm{V}_{\mathrm{T}}$ delivery, which is conducted at such a value of CDP that ensures the best oxygenation and also carbon dioxide removal. The average $\mathrm{V}_{\mathrm{T}}$ for normocapnic HFOV at $5 \mathrm{~Hz}$, calculated gradually during the study group formation, was about $2 \mathrm{ml} / \mathrm{kg}$. In each new case of HFOV application the pressure amplitude $\Delta \mathrm{P}$ of the ventilator was set so that the delivered tidal volume in the initial phase of HFOV would be equal to this determined normocapnic value. The tidal volume monitoring was useful during whole periods of HFOV for the maintenance of normocapnia. The continuous monitoring of airway resistance also warned us about possible problems with patency of the airways. In comparison with conventional ventilation, any change of the airway resistance negatively affects the delivered tidal volume more strongly during HFOV (Roubík et al. 2004). We realized the clinical importance of this monitoring especially in some extraordinary cases, where the HFOV monitoring system was unavailable.

Between years 2000-2003, we indicated 30 ARDS patients for HFOV. All patients were switched to HFOV after failure of conventional ventilation in order to improve their oxygenation status $\left(\mathrm{P}_{\text {plateau }}>3.5 \mathrm{kPa}\right.$, PEEP $>1 \mathrm{kPa}$ and $\mathrm{F}_{\mathrm{I}} \mathrm{O}_{2}>0.6$ while $\mathrm{V}_{\mathrm{T}}<8 \mathrm{ml} / \mathrm{kg}$ ). The main reason of the presented significant difference in duration of CMV before HFOV between the studied groups is caused by a different time course in progression of respiratory failure in patients with bilateral pneumonia. Based on our experience these patients reach the criteria for HFOV later in comparison with $\mathrm{ARDS}_{\text {exp }}$ patients. There were also six cases of pulmonary type of ARDS in oncohematological patients involved in our study. Assignment of an ARDS type in these patients is not always obvious and the HFOV effect in these patients is generally lower. It is caused by the cytotoxic effect of the current regimens of the induction therapy, (graft versus host disease in the case of stem cell transplantation, decay of myelocytes, etc., resulting in a further lung injury, fibroproliferation and worse reparatory abilities of the pulmonary parenchyma.

Except for the above mentioned time parameter we found no significant difference in mean airway pressure (MAP), compliance of the respiratory system, hypoxemic index before HFOV, oxygenation index (OI) in the starting time of HFOV and lung injury score (LIS) between the groups. 
After reaching the normocapnic values we observed that HFOV took a positive effect immediately in some patients, contrary to others, where the HFOV effect was minimal or even negative. The evaluation of oxygenation trend changes (Fig. 5) persuaded us that if there is no reasonable improvement in oxygenation within 12-24 hours, the further continuation of HFOV would be futile. This is in agreement with the findings recently published by David et al. (2003). In "nonresponders" we discontinued HFOV within the period of first 6-24 hours of HFOV. The significant difference in duration of HFOV application in the studied groups also clearly documents the different effects of this unconventional ventilatory approach.

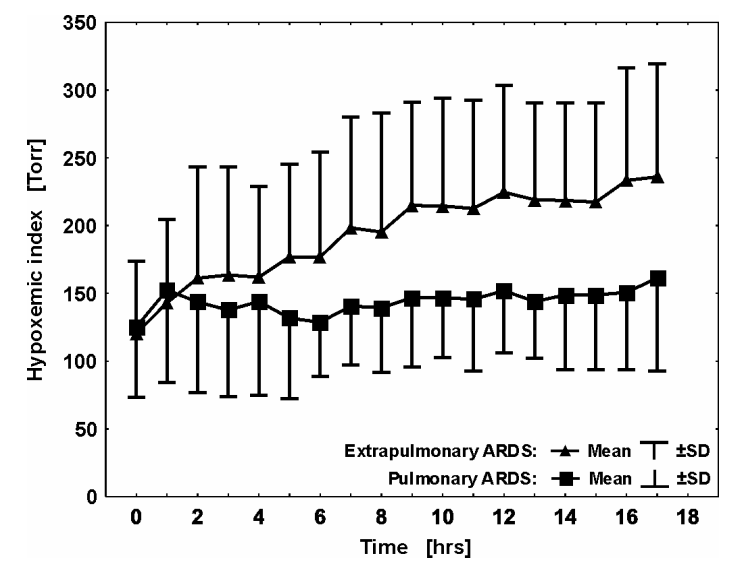

Fig. 5. Hypoxemic index during the first 17 hours of HFOV in pulmonary and extrapulmonary ARDS groups; values at a time of $0 \mathrm{hrs}$ represent the latest hypoxemic indexes recorded at the end of the preceding conventional mechanical ventilation

Our results also correlate with the results of the EMOAT multicenter study (Well et al. 2002), in which patients with a high oxygenation index $(\mathrm{OI}>20)$ form a target group for HFOV. If we retrospectively select the patients with a definitely positive HFOV effect, we create a group of patients characterized by a short-time history of respiratory insufficiency, extrapulmonary ARDS and OI $>20$. The criterion of OI $>20$ predicts that HFOV will be effective (with a probability higher than $90 \%$ in our group of patients). Nevertheless, the criterion is too strict, because approximately a half of the remaining patients can still take advantage of $\mathrm{HFOV}$ (increase in $\mathrm{PaO}_{2} / \mathrm{F}_{\mathrm{I}} \mathrm{O}_{2}$ $>10 \%$ during HFOV).

The significant differences in hypoxemic indexes (best $\mathrm{PaO}_{2} / \mathrm{F}_{\mathrm{I}} \mathrm{O}_{2}$ index, $\mathrm{PaO}_{2} / \mathrm{F}_{\mathrm{I}} \mathrm{O}_{2}$ index after 6 hours of HFOV, mean $\mathrm{PaO}_{2} / \mathrm{F}_{\mathrm{I}} \mathrm{O}_{2}$ index and the oxygen gain values) during HFOV document a significantly

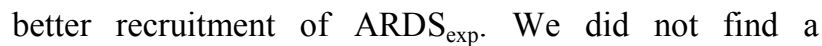
significant difference in OI between the groups. This result is affected by parameters involved in OI calculation, particularly continuous distension pressure during HFOV, changes in oxygenation and the protocol design as well.

Very significant differences in initial optimal CDP level between 1 and $4.5 \mathrm{kPa}$ were observed within the study group. Severe extrapulmonary forms of ARDS required high initial CDP levels, generally above $3 \mathrm{kPa}$. These high CDP levels were very well tolerated by the circulatory system in comparison with conventional mechanical ventilation in which the introduction of a high end-expiratory pressure and increase in mean airway pressure lead frequently to the circulatory insufficiency and necessity of vasopressor administration. On the other hand, in pulmonary forms of ARDS the optimal continuous distension pressure is very often at a lower level. We recorded two cases when optimal CDP was even lower than mean airway pressure during preceding conventional ventilation. We still consider the publication of Gattinoni et al. (1998) as the basis for understanding the HFOV effect. In this conventional ventilation study the difference between pulmonary and extrapulmonary injury is described, based on analysis of the characteristic mechanical parameters of the chest wall and lungs. We presume that a sufficient expansion of the chest is ensured by the continuous and relatively high CDP. The chest wall expansion creates enough space for the lung expansion and recruitment of the distal compartments of the respiratory system. Another interesting finding in the cited work is a possibility to distinguish between $\operatorname{ARDS}_{\mathrm{p}}$ and $\mathrm{ARDS}_{\text {exp }}$ cases according to intraabdominal pressure values, which are significantly lower in $\mathrm{ARDS}_{\mathrm{p}}$. Nevertheless, considering different mechanical effects of PEEP or MAP during CMV and CDP during HFOV, further investigation should be conducted in order to confirm this possible classification criterion in the course of HFOV. Therefore, the effect of CDP on intraabdominal pressure should be evaluated.

During conventional ventilation there is enough time for the intrapulmonary pressure to equal the proximal pressure. Therefore, at the end of expiration, the alveolar pressure is equal to the proximal value of endexpiratory pressure (PEEP). PEEP is the only distension pressure acting through the whole ventilatory cycle and in some cases it is not high enough for maintaining airways and lungs opened. This effect is obvious especially in injuries requiring a high CDP during HFOV. In several 
patients, the optimal CDP was found at a higher level than is the level recommended for safe conventional recruitment maneuvers. One patient in our study required optimal CDP of $4.5 \mathrm{kPa}$.

Intrapulmonary situation is completely different in HFOV. The alveolar pressure does not keep up with changes of the proximal pressure and the amplitude of the alveolar pressure in HFOV is minimal. The actual value of the pressure amplitude is dependent on mechanical properties of the lung and chest wall, ventilatory frequency, and other parameters. The amplitude of the alveolar pressure for a healthy lung does not reach even $10 \%$ of the proximal pressure amplitude $(\Delta \mathrm{P})$ (Roubík et al. 2004). Therefore the continuous distension pressure operates during the entire breathing cycle. It is possible to presume that a risk of the development of dynamic endexpiratory pressure and consequently a risk of ventilator induced lung injury (VILI) is decreased in comparison with conventional mechanical ventilation if patency of the airways is maintained. We can state that we had 39 HFOV applications in adults (including the repeated applications) and all of them without HFOV developed pneumothorax.

According to the presented results (Fig. 4), the initial optimal CDP in comparison with MAP can be used for a prediction of HFOV efficacy. Nevertheless, this criterion can be applied after HFOV initiation, not during CMV. Initial CDP values were set according to the standard recommendation, which is $0.5 \mathrm{kPa}$ above MAP used during preceding conventional mechanical ventilation. In patients with a positive reaction to HFOV, the calculated starting CDP was too low and it was necessary to increase the CDP level in order to improve oxygenation. In patients not performing a positive HFOV effect, the optimal CDP for oxygenation rests in a close vicinity of the recommended calculated value (MAP + $0.5 \mathrm{kPa}$ ). It is also interesting that the initial optimal CDP would be used for differentiation between pulmonary and extrapulmonary forms of ARDS. The classification is based on the analysis of the mechanical parameters of the chest wall and lungs. We mentioned this difference during the evaluation of lung compliance at different levels of end-expiratory pressure. In the first group of patients the lung compliance did not change significantly, in the second group the increasing end-expiratory pressure caused a rapid increase in compliance. This second group, where lung compliance varies rapidly, can be considered as the group of patients with extrapulmonary ARDS requiring higher CDP levels.
Finally, we should come back to the recently discussed problems of HFOV. We consider the lung injury with a dominance of interstitial edema and liquid present in the alveoli, consequently causing collapse of alveoli with a low compliance of the chest wall, optimal for treatment by HFOV. Our results support the previously presented findings (Mehta et al. 2001) about early HFOV usage. Our experience supports the normocapnic strategy with primary stepwise decrease of oxygen fraction to $\mathrm{F}_{\mathrm{I}} \mathrm{O}_{2}=0.4$ and secondary $\mathrm{CDP}$ stepwise depletion regulated by the lung-recruitment stability, which is generally reached in one week period. In our opinion the acceptable value of CDP for conversion to $\mathrm{CMV}$ is about $1.8-2 \mathrm{kPa}$ in adult patients.

\section{Conclusion}

\begin{abstract}
Normocapnic high frequency oscillatory ventilation affects $\mathrm{ARDS}_{\mathrm{p}}$ and $\mathrm{ARDS}_{\text {exp }}$ patients differently. Better recruitment of $\mathrm{ARDS}_{\exp }$ lungs is documented by a statistically significant increase in values of $\mathrm{PaO}_{2} / \mathrm{F}_{\mathrm{I}} \mathrm{O}_{2}$ index. When $\mathrm{HFOV}$ is effective, acceptable oxygenation parameters are reached within 24 hours at $\mathrm{F}_{\mathrm{I}} \mathrm{O}_{2}=0.4$. Nevertheless, the distension therapy may be required for the next several days. We presume that conventional ventilators with a possibility of measurement of lung and chest wall compliance will be necessary for a proper indication of this unconventional ventilatory regimen.
\end{abstract}

\section{Abbreviations}

$\Delta \mathrm{P}$ - pressure amplitude, ARDS - acute respiratory distress syndrome, $\mathrm{ARDS}_{\mathrm{p}}$ - pulmonary ARDS, $\mathrm{ARDS}_{\exp }$ - extrapulmonary ARDS, $\mathrm{C}_{\mathrm{rs}}$ - compliance of the respiratory system, CDP - continuous distension pressure, CMV - conventional mechanical ventilation, $\mathrm{f}$ ventilatory rate, $\mathrm{F}_{1} \mathrm{O}_{2}$ - inspiratory oxygen fraction, HFOV - high-frequency oscillatory ventilation, LIS lung injury score, MAP - mean airway pressure, OI oxygenation index, PEEP - positive end-expiratory pressure, $\mathrm{PaCO}_{2}$ - arterial $\mathrm{CO}_{2}$ partial pressure, $\mathrm{PaO}_{2}$ arterial $\mathrm{O}_{2}$ partial pressure, $\mathrm{PaO}_{2} / \mathrm{F}_{\mathrm{I}} \mathrm{O}_{2}$ - hypoxemic index, PCWP - pulmonary capillary wedge pressure, $\mathrm{pH}$ arterial blood acidity, $\mathrm{P}_{\text {plateau }}$ - proximal airway pressure during inspiratory plateau, PIP - peak inspiratory pressure, $\mathrm{R}_{\mathrm{aw}}$ - airway resistance, $\mathrm{SD}$ - standard deviation, $\mathrm{T}_{\mathrm{I}} / \mathrm{T}$ - relative inspiratory period, $\mathrm{V}_{\mathrm{T}}$ - tidal volume 


\section{Acknowledgements}

The study was supported by grants IGA NR8078-3 and

MSMT CR MSM6840770012.

\section{References}

ANDERSEN FA, GUTTORMSEN AB, FLAATTEN HK: High frequency oscillatory ventilation in adult patients with acute respiratory distress syndrome--a retrospective study. Acta Anaesthesiol Scand 46: 1082-1088, 2002.

BELOUCIF S, PAYEN D: A European survey of the use of inhaled nitric oxide in the ICU. Working Group on Inhaled NO in the ICU of the European Society of Intensive Care Medicine. Intensive Care Med 24: 864-877, 1998.

BERNARD GR, ARTIGAS A, BRIGHAM KL, CARLET J, FALKE K, HUDSON L, LAMY M, LEGALL JR, MORRIS A, SPRAGG R: The American-European Consensus Conference on ARDS. Definitions, mechanisms, relevant outcomes, and clinical trial coordination. Am J Respir Crit Care Med 149: 818-824, 1994.

DAVID M, WEILER N, HEINRICHS W, NEUMANN M, JOOST T, MARKSTALLER K, EBERLE B: Highfrequency oscillatory ventilation in adult acute respiratory distress syndrome. Intensive Care Med 29: 1656$1665,2003$.

DERDAK S, MEHTA S, STEWART TE, SMITH T, ROGERS M, BUCHMAN TG, CARLIN B, LOWSON S, GRANTON J: High-frequency oscillatory ventilation for acute respiratory distress syndrome in adults: a randomized, controlled trial. Am J Respir Crit Care Med 166: 801-808, 2002.

FERGUSON ND, STEWART TE: The use of high-frequency oscillatory ventilation in adults with acute lung injury. Respir Care Clin N Am 7: 647-661, 2001.

FORT P, FARMER C, WESTERMAN J, JOHANNIGMAN J, BENINATI W, DOLAN S, DERDAK S: Highfrequency oscillatory ventilation for adult respiratory distress syndrome - a pilot study. Crit Care Med 25: 937947, 1997.

GATTINONI L, PELOSI P, SUTER PM, PEDOTO A, VERCESI P, LISSONI A: Acute respiratory distress syndrome caused by pulmonary and extrapulmonary disease. Different syndromes? Am J Respir Crit Care Med 158: 3-11, 1998.

INTERNATIONAL CONSENSUS CONFERENCES IN INTENSIVE CARE MEDICINE: Ventilator-associated lung injury in ARDS. Am J Respir Crit Care Med 160: 2118-2124, 1999.

LIM CM, KIM EK, LEE JS, SHIM TS, LEE SD, KOH Y, KIM WS, KIM DS, KIM WD: Comparison of the response to the prone position between pulmonary and extrapulmonary acute respiratory distress syndrome. Intensive Care Med 27: 477-485, 2001.

MEHTA S, LAPINSKY SE, HALLETT DC, MERKER D, GROLL RJ, COOPER AB, MACDONALD RJ, STEWART TE: Prospective trial of high-frequency oscillation in adults with acute respiratory distress syndrome. Crit Care Med 29: 1360-1369, 2001.

INTERNATIONAL CONSENSUS CONFERENCES IN INTENSIVE CARE MEDICINE: Ventilator-associated Lung Injury in ARDS. Am J Respir Crit Care Med 160: 2118-2124, 1999.

PACHL J, BROŽ L, KRIPNER J, FRIČ M, ROUBÍK K, ZÁBRODSKÝ V, WALDAUF P, BAKALÁŘ B, HORÁKOVÁ O, JANDOVÁ J, KOENIGOVÁ R: Initial optimal HFOV continuous distension pressure in prone in a paediatric burn: case Report. Burns 30: 192-196, 2004.

PELOSI P, CAIRONI P, TACCONE P, BRAZZI L: Pathophysiology of prone positioning in the healthy lung and in ALI/ARDS. Minerva Anestesiol 67: 238-247, 2001.

PUGIN J, RICOU B, STEINBERG KP, SUTER PM, MARTIN TR: Proinflammatory activity in bronchoalveolar lavage fluids from patients with ARDS, a prominent role for interleukin-1. Am J Respir Crit Care Med 153: 1850-1856, 1996.

ROUBÍK K, KREJZL J, ZÁBRODSKÝ V: Real time monitoring and evaluation system for high frequency ventilation. In: Proceedings 8th International IMEKO Conference on Measurement in Clinical Medicine, Biomedical Measurement and Instrumentation. Dubrovnik - KoREMA, Zagreb, 1998, pp 19-22. 
ROUBÍK K, ROŽÁNEK M, KOPELENT V, PACHL J: Use of the human respiratory system models to explain HFV effects observed in clinical practice. Intensive Care Med 30 (Suppl 1): S154, 2004.

SINGH JM, MEHTA S, KACMAREK RM: Pro/con clinical debate: is high-frequency oscillatory ventilation useful in the management of adult patients with respiratory failure? Crit Care 6: 183-185, 2002.

WELL GTJ, BOLLEN CW, SHERRY T, BEALE RJ, SHAH S, FINDLAY G, MONCHI M, CHICHE JD, VUGHT AJ: HFOV compared to CMV improves outcome in severe ARDS. Proceedings of the $6^{\text {th }}$ European Conference on Pediatric and Neonatal Ventilation. Book of Abstract, NICU (ed), C.H.V.E., Recourt IV., p 5, 2002.

\section{Reprint requests}

J. Pachl, University Department of Anesthesiology and Resuscitation, Šrobárova 50, 10034 Prague 10, Czech Republic.

E-mail: pachl@fnkv.cz 